\title{
Calidad Físico-Química de las Aguas Superficiales de la Subcuenca del Río Viejo
}

Selvia Flores Sánchez

Centro para la Investigación en Recursos Acuáticos de Nicaragua, CIRA/UNAN-Managua. selvia.flores@cira-unan.edu.ni

\section{RESUMEN}

Se evaluó la calidad del agua desde el punto de vista físicoquímico, de nutrientes, del contenido de las variables indicadoras de contaminación por materia orgánica (DBO5 y DQO), así como de contaminantes metálicos y orgánicos en las fuentes superficiales de la subcuenca del Río Viejo en relación a su adaptabilidad para los diferentes usos. Los resultados del análisis físico - químico casi en todos los sitios de muestreo revelaron valores que le confieren al agua características óptimas en cuanto a su utilización para riego, recreación y protección de la vida acuática, siendo particularmente para el río El Jordán de buena calidad para consumo humano. Sin embargo, es importante contrastar con los indicadores microbiológicos de contaminación. Los contaminantes metálicos (cadmio, arsénico y mercurio) se detectaron en algunos sitios en concentraciones ligeramente mayores al límite de detección de los métodos analíticos, siendo muy inferiores a los valores de referencia para aguas no contaminadas, lo que hace presumir su origen natural. La detección de los plaguicidas Dieldrín y Endrín en valores similares a los recomendados para la protección de la vida acuática, sugiere que sea producto, tanto de la persistencia de los mismos en el suelo por su amplia utilización en el pasado, como de utilización actual, no obstante su prohibición. En general todos los sitios de muestreo presentaron diferente grado de afectación por el aporte externo de nutriente. De manera excepcional, se identificó Trinidad-Casco Urbano como el sitio en condiciones ambientalmente críticas en su condición de receptor natural de aguas residuales domésticas con valores altos de DBO5 y DQO, así como por la presencia de varios compuestos organoclorados.

Palabras Claves: macroconstituyentes, tipo hidroquímico, nutrientes, aportes externos, riego.

\section{INTRODUCCIÓN}

La evaluación de los recursos hídricos en cuanto a su calidad, su gestión y monitoreo representa la garantía de un desarrollo socioeconómico sustentable y armónico con el medio ambiente. Haciendo referencia particular a las fuentes superficiales, cuando se desarrollan actividades en su área de drenaje sobre las que se ejerce poco o ningún control, el impacto negativo sobre la calidad del agua se reflejará en la restricción de la diversidad de usos que ellas representan.

Actualmente, la creciente demanda por las fuentes superficiales de la subcuenca del Río Viejo y de su utilización como cuerpos receptores de desechos líquidos y sólidos, tanto de los cursos de zonas rurales como de aquellos que atraviesan importantes sectores urbanos, puede estar afectando la calidad del agua.

Consecuentemente, esto implicaría serias restricciones en relación a los múltiples usos que éstas brindan (consumo humano, agrícola, pecuario, recreación, etc.,) y así del desarrollo económico en esta región.

Por lo anterior, en este estudio se han involucrado, además de las variables propias de los cuerpos de agua que igualmente pueden ser alteradas por factores externos de origen antropogénico, aquellas inducidas a través de vertidos residuales generados por las actividades humanas, las cuales se utilizan como indicadoras de contaminación (sólidos suspendidos, nutrientes, DBO5, DQO, metales pesados y plaguicidas).

En el marco del Estudio de la Calidad y Disponibilidad de los Recursos Hídricos en la Subcuenca del Río Viejo, evaluar la calidad del agua desde el punto de vista físicoquímico y del contenido de variables indicadoras de contaminación en las fuentes superficiales de la subcuenca del Río Viejo, permitirá caracterizar la naturaleza de sus aguas, determinar su adaptabilidad para los diferentes usos e identificar áreas críticas. Este aporte técnico-científico del Centro para la Investigación en Recursos Acuáticos de Nicaragua (CIRA/UNANManagua), generado en alianza con el Proyecto Integral de Manejo de Cuencas Hidrográficas, Agua y Saneamiento (MARENA-PIMCHAS), proporcionará al Proyecto herramientas que podrán ser utilizadas para el establecimiento de planes de manejo de los recursos hídricos en la zona.

\section{MATERIALES Y MÉTODOS}

\section{Área de estudio}

La subcuenca del Río Viejo tiene un área aproximada de $1553 \mathrm{~km} 2$, se encuentra dentro de la cuenca hídrica de los 
Grandes Lagos y Río San Juan, cuenca No. 69, (figura 1), la cual drena hacia la vertiente del Atlántico y es la más extensa del país $(29,824 \mathrm{~km} 2)$. El área de estudio cuenta con una serie de microcuencas, de ríos intermitentes en su mayoría, abarca parcialmente doce municipios en los departamentos de Jinotega, Estelí, Matagalpa, León y Managua (CIRA/UNAN-Managua, 2012). El Río Viejo nace en el municipio de San Rafael del Norte (MARENA, 2008), tiene una longitud aproximada de 157 km y descarga al Lago Xolotlán (CIRA/UNANManagua, 2012).

\section{Sitios de muestreo}

Se seleccionaron de forma preliminar 11 sitios distribuidos en la red fluvial de la subcuenca del Río Viejo en base a su localización respecto a la variabilidad de actividades que se desarrollan en su área, tanto en cursos de zonas rurales como de aquellos que atraviesan importantes sectores urbanos, 7 de los cuales se ubicaron en tributarios y 4 sobre la corriente principal.

En estos sitios se recopiló información que consistió en mediciones de campo (temperatura, oxígeno disuelto, $\mathrm{pH}$ y conductividad eléctrica) y colecta de agua para análisis de nutrientes (formas totales de nitrógeno y fósforo).

La información anterior sirvió para redefinir finalmente dieciséis sitios de muestreo, cuya localización fue en 9 tributarios y 6 sobre la corriente principal del Río Viejo. Con los sitios El Jordán y río Grande en MELONICSA en el extremo superior e inferior respectivamente de la red fluvial, se abarcó desde un área próxima a la cabecera del río hasta antes de su desembocadura en el lago Xolotlán (figura 1).

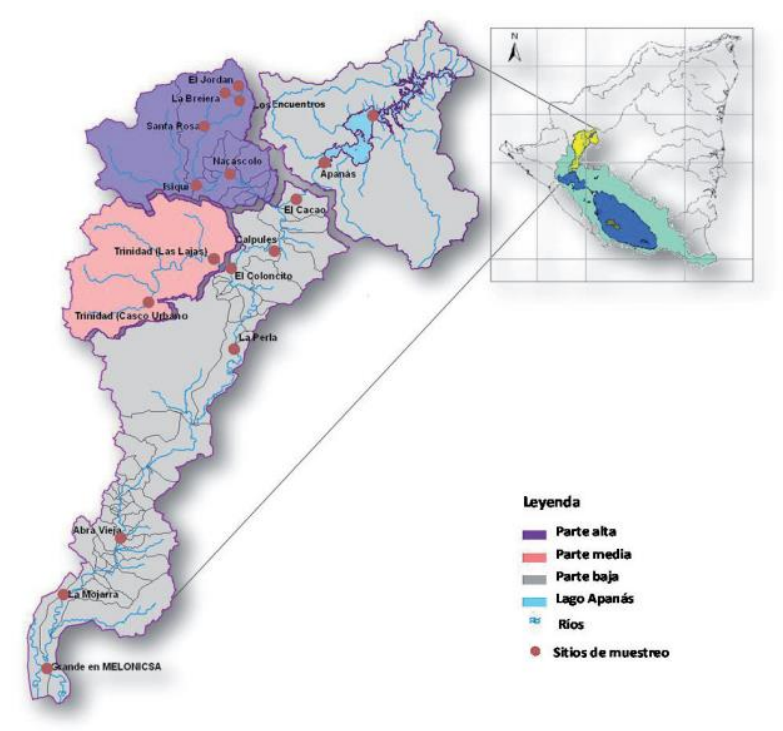

Figura 1. Ubicación del área de estudio: Subcuenca del Río Viejo (partes alta, media y baja)
Adicionalmente para totalizar los dieciséis sitios, se integró el lago Apanás, que es un embalse utilizado para la generación de energía hidroeléctrica, ya que el agua que descarga a través del Río El Cacao llega directamente a la corriente principal del Río Viejo que escurre por toda la parte baja de la subcuenca, siendo un aspecto importante a considerar sobre este tramo.

\section{Muestreo y análisis realizados}

Un muestreo preliminar se realizó en noviembre de 2009, cuando el flujo se encontraba aún bajo la influencia de las lluvias, cuya época transcurre de mayo a octubre y eventualmente hasta noviembre.

Posteriormente, se colectaron muestras de agua y sedimento en marzo de 2010 y en enero de 2011 en los dieciséis sitios redefinidos para este estudio. Considerando las posibles variaciones estacionales de las corrientes superficiales, estos dos eventos correspondieron el primero a la época seca cuando fluye el caudal base y el segundo a la época de lluvias debido a que la presencia del fenómeno meteorológico de La Niña hizo que se prolongara el periodo de las precipitaciones.

Las muestras de agua para realizar los análisis físicoquímicos, de sólidos (totales, disueltos y suspendidos), de nutrientes (nitrógeno total, fósforo total y ortofosfato), $\mathrm{DBO}_{5}$ y DQO, de contaminantes orgánicos (plaguicidas organoclorados, organofosforados y carbamatos) y contaminantes metálicos (arsénico, cadmio y mercurio), éstos últimos también en sedimento, se colectaron siguiendo los procedimientos del laboratorio de Aguas Naturales, Aguas Residuales, Contaminantes Orgánicos y Contaminantes Metálicos referidos a técnicas, preservación, almacenamiento y transporte.

Todas las determinaciones analíticas se basaron en la metodología descrita en los Procedimientos Operativos Normalizados (PON) de los laboratorios involucrados del CIRA/UNAN-Managua. Estos procedimientos se basan en American Public Health Association, APHA (2005) para las variables físico-químicas...formas nitrogenadas inorgánicas disueltas y fosforadas; Rodier (1981) para amonio y Crumpton (1992) para el nitrógeno total.

Para los contaminantes metálicos en sus formas totales, los procedimientos se basan en American Public Health Association, APHA (2005), los cuales fueron analizados por Espectrometría de Absorción Atómica, utilizando la variante con Horno de Grafito (VARIAN SpectrAA240Z, GTA-120) para el cadmio en agua y con Llama en sedimento (VARIAN SpectrAA-240FS); con Generación de Hidruros para el arsénico y con Generación de Vapor Frío para el mercurio (VARIAN SpectrAA-240FS, VGA77), ambos en agua y sedimento. 
Los plaguicidas se analizaron por cromatografía de gases equipados con columnas capilares DB-5 y VF-5 MS, detectores de captura de electrones (ECD) y espectrometría de masas (MS) para el grupo de organoclorados $\mathrm{y}$ organofosforados $\mathrm{y}$ con columna capilar DB-1701 y detector termoiónico especifico (TSD) para los carbamatos.

Los resultados de las variables analizadas se compararon con valores y criterios establecidos por Normas Regionales e Internacionales en función de los diferentes usos: Consumo humano (CAPRE, 1994), (World Health Organization (WHO), 2008), irrigación de cultivos agrícolas (Ayers \& Wescot, 1984), (U.S. Salinity Laboratory Staff, 1954) y preservación de la vida acuática (Canadian Counsil of Ministers of the Environment (CCME), 2008).

\section{RESULTADOS DISCUSIÓN}

\section{Condiciones físico - químicas y de nutrientes}

En casi todos los sitios de muestreo, tanto tributarios como corriente principal, se determinaron valores óptimos de oxígeno disuelto $(5,0$ a $9,44 \mathrm{mg} .1$ 1), de $\mathrm{pH} \quad(6,84$ a 8,35$)$ característicos para aguas dulces (Custodio \& Llamas, 2001), así como condiciones de baja turbidez por presentar valores menores que 50 UNT (Canadian Counsil of Ministers of the Environment (CCME), 2008). Solamente Trinidad-Casco

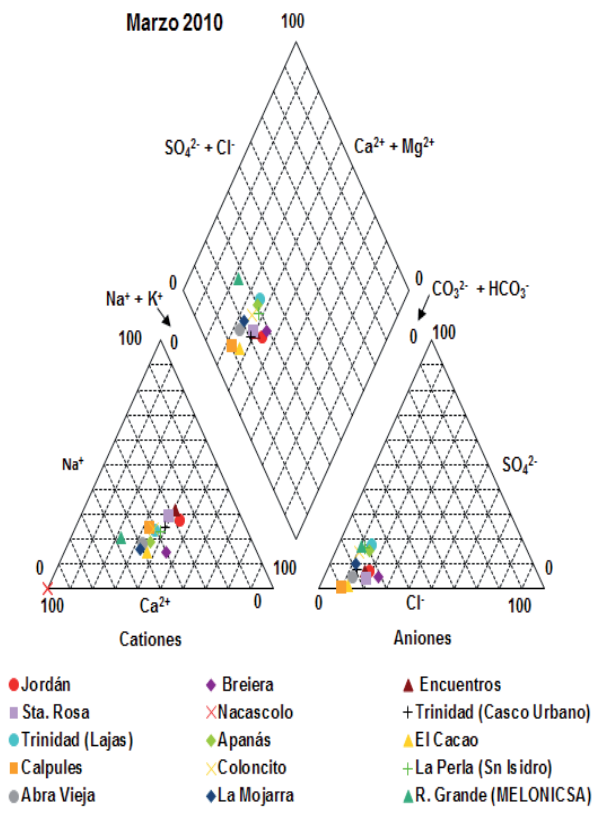

incrementos en la época seca (marzo de 2010) y disminuciones en la época lluviosa en respuesta a las variaciones inducidas por los cambios estacionales del régimen hidrológico, siendo el efecto de los procesos de concentración y dilución respectivamente. Asimismo, son aguas de baja mineralización (conductividad eléctrica < $200 \mu$ S.cm-1) y blandas ( $<75$ mg.l-1 de dureza total como $\mathrm{CaCO}_{3}$ ) (Roldán \& Ramírez, 2008), exceptuando Nacascolo en la parte alta de la subcuenca, así como Trinidad Casco-Urbano y Trinidad en Las Lajas en la parte media que presentaron mayores niveles de mineralización, cuyo contenido en general de iones mayores $\left(\mathrm{Ca}_{2+}, \mathrm{Mg}_{2+}, \mathrm{Na}_{+}, \mathrm{K}_{+}, \mathrm{Cl}-, \mathrm{SO}_{4} 2-, \mathrm{HCO}_{3}\right.$-) fue característico para aguas dulces.
Urbano (parte media de la subcuenca) en calidad de cuerpo receptor de aguas residuales domésticas presentó niveles bajos de oxígeno (4,1 mg.l-1); La Perla y Calpules (parte baja de la subcuenca) con la mayor turbidez (61 UNT) debido al efecto de una permanentemente alta turbulencia. Si bien, el color verdadero tiene importancia de orden estético para aguas de consumo humano (World Health Organization (WHO), 2008), de manera general en todos los sitios de muestreo y particular para El Jordán por su utilización como fuente de abastecimiento, fue mayor al valor recomendado (1,0 mg.1-1Pt-Co), siendo sin embargo para este sitio, inferior respecto al valor máximo admisible (15 mg.l-1 Pt-Co) (CAPRE, 1994).

De acuerdo a los sólidos suspendidos totales, el agua se categorizó de buena calidad en la parte alta y desde muy buena a normal en la parte media y baja de la subcuenca (Ramirez \& Viña, 1998). Las sales minerales disueltas exhibieron a grandes rasgos la existencia de patrones de distribución temporal que se manifestaron con

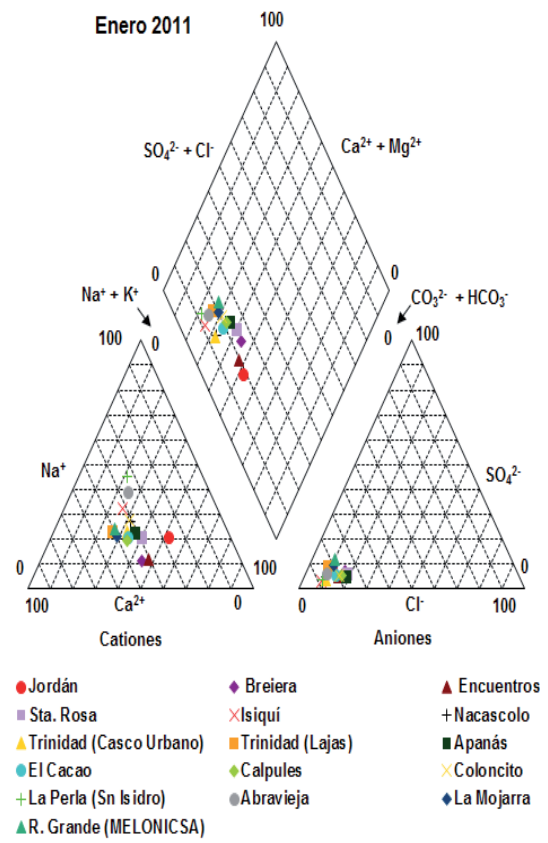

Figura 2. Diagrama de Piper: Tipo hidroquímico de fuentes superficiales en la subcuenca del Río Viejo.

El tipo hidroquímico que dominó fue el bicarbonatadocálcico $\left(\mathrm{HCO}_{3}-\mathrm{Ca}\right)$, indicador de una formación rocosa predominantemente caliza del área de drenaje, exceptuando El Jordán que fue $\mathrm{HCO}_{3}-\mathrm{Na}$ debido a su localización en la zona de recarga (figura 2).

En cada sitio de muestreo, al menos una de las tres formas nitrogenadas inorgánicas disueltas (nitratos, nitritos y amonio) se cuantificó en niveles que excedieron los valores y rangos de referencia para ríos no contaminados (Wetzel, 2001), siendo la parte media y baja de la subcuenca los tramos más afectados respecto a los nitratos y amonio (tabla 1). Aquí se identificaron las prácticas pecuarias manejadas de manera inadecuada y el vertido de aguas residuales domésticas como las actividades que mayormente contribuyen. 
Tabla 1. Concentración de las formas inorgánicas nitrogenadas disueltas: nitratos $\left(\mathrm{N}-\mathrm{NO}_{3}\right)$, nitritos $\left(\mathrm{N}-\mathrm{NO}_{2}\right)$ y amonio $\left(\mathrm{N}-\mathrm{NH} \mathrm{H}_{4}\right)$ en las fuentes superficiales de la subcuenca del Río Viejo.

\begin{tabular}{|c|c|c|c|c|c|c|c|}
\hline \multicolumn{2}{|r|}{ Subcuenca } & \multicolumn{2}{|c|}{$\mathrm{N}-\mathrm{NO}_{3}\left(\mathrm{mg} \cdot \mathrm{I}^{-1}\right)$} & \multicolumn{2}{|c|}{$\mathrm{N}-\mathrm{NO}_{2}\left(\mathrm{mg} . \mathrm{I}^{-1}\right)$} & \multicolumn{2}{|c|}{$\mathrm{N}-\mathrm{NH}_{4}\left(\mathrm{mg} . \mathrm{I}^{-1}\right)$} \\
\hline Parte & Sitios de muestreo & mar-10 & ene-11 & mar-10 & ene-11 & mar-10 & ene-11 \\
\hline \multirow{6}{*}{$\frac{\pi}{4}$} & El Jordán & $<0,011$ & $<0,011$ & 0,001 & 0,001 & $<0,004$ & 0,046 \\
\hline & La Breiera & $<0,011$ & $<0,011$ & 0,001 & 0,002 & 0,048 & 0,023 \\
\hline & Los Encuentros & $<0,011$ & $<0,011$ & $<0,001$ & 0,002 & 0,021 & 0,027 \\
\hline & Santa Rosa & $<0,011$ & 0,456 & 0,003 & 0,004 & 0,059 & 0,017 \\
\hline & Isiquí & & $<0,011$ & & 0,002 & & 0,028 \\
\hline & Nacascolo & 0,061 & $<0,011$ & 0,002 & 0,004 & 0,057 & 0,029 \\
\hline \multirow{2}{*}{ Media } & Trinidad-Casco Urbano & 1,070 & $<0,011$ & 0,007 & 0,027 & 1,362 & 0,110 \\
\hline & Trinidad-Las Lajas & 0,090 & $<0,011$ & 0,002 & 0,003 & 0,058 & 0,030 \\
\hline \multirow{8}{*}{$\stackrel{\pi}{\frac{\pi}{\pi}}$} & Apanás & 0,005 & 0,431 & 0,012 & 0,007 & 0,045 & 0,039 \\
\hline & El Cacao & $<0,011$ & 0,350 & 0,002 & 0,008 & 0,017 & 0,028 \\
\hline & Calpules & $<0,011$ & 0,379 & 0,004 & 0,009 & 0,033 & 0,054 \\
\hline & Coloncito & $<0,011$ & 0,379 & 0,016 & 0,005 & 0,061 & 0,029 \\
\hline & La Perla & $<0,011$ & 0,485 & 0,018 & 0,004 & 0,055 & 0,022 \\
\hline & AbraVieja & $<0,011$ & $<0,011$ & 0,003 & 0,002 & 0,029 & 0,023 \\
\hline & La Mojarra & $<0,011$ & $<0,011$ & 0,002 & 0,014 & 0,048 & 0,021 \\
\hline & Grande en MELONICSA & 0,050 & 0,291 & 0,002 & 0,017 & 0,054 & 0,044 \\
\hline \multicolumn{2}{|c|}{ Distribución en ríos no contaminados } & \multicolumn{2}{|c|}{$0,05-0,2$} & \multicolumn{2}{|c|}{0,001} & \multicolumn{2}{|c|}{$0,005-0,04$} \\
\hline
\end{tabular}

La baja relación N:P (nitrógeno:fósforo) obtenida principalmente durante las lluvias en niveles que usualmente están asociados con fuentes puntuales de contaminación, donde el fósforo figura como el mayor contribuyente, se vinculó directamente con las actividades que se realizan en los sectores aledaños a los sitios de muestreo, siendo los más afectados: Santa Rosa $(3,7: 1)$ y Nacascolo $(2,5: 1)$ en la parte alta por aguas grises y escorrentía de suelos fertilizados; Trinidad-
Casco Urbano $(1,1: 1)$ y Trinidad - Las Lajas $(1,7: 1)$ en la parte media por vertidos domésticos; así como Río Grande en MELONICSA $(3,4: 1)$ localizado en el tramo final del Río Viejo, por aguas de retorno de zonas agrícolas (enriquecidas con nutrientes) y receptor final de la red fluvial. En contraste, el lago Apanás reflejó altas relaciones ( $>25: 1$ ), indicadoras de fuentes no puntuales de contaminación que llegan a través de la escorrentía procedente de extensas áreas agrícolas y ganaderas. 
Según lo observado in situ, la deposición directa de las heces del ganado y las aguas grises sobre las corrientes de las zonas rurales, además del escurrimiento natural desde suelos fertilizados cercanos a los ríos se identificaron entre los principales aportadores de nutrientes (nitrógeno total, fósforo total y ortofosfato) y resultado del poco o ningún control sobre las actividades humanas que se desarrollan en la subcuenca. En consecuencia, en todos los sitios de muestreo se generaron concentraciones de fósforo total (PT) mayores al valor de referencia (0,050 mg.1-1) de la Agencia de Protección Ambiental de los Estados Unidos (USEPA) para prevenir el proceso de eutrofización en corrientes superficiales que descargan en lagos.

La mayor concentración de $\mathrm{DBO}_{5}$ y DQO se cuantificó para el tramo de Trinidad - Casco Urbano durante la época seca (figura 3), cuyo impacto se reflejó a través de los niveles más bajos de OD (4,1 mg.1-1) que se presentaron en respuesta a una mayor demanda, paralelamente a condiciones ambientales críticas vinculadas con el vertido de aguas residuales domésticas sin tratar. Asimismo, a juzgar por los resultados de DBO5 y DQO obtenidos en enero de 2011 cuando las lluvias revelaron un efecto regulador sobre TrinidadUrbano, la pérdida de la capacidad de autodepuración de la corriente en la época seca, se debe a la fuerte influencia de los aportes antropogénicos, más que por

$\mathrm{DBO}_{5}$

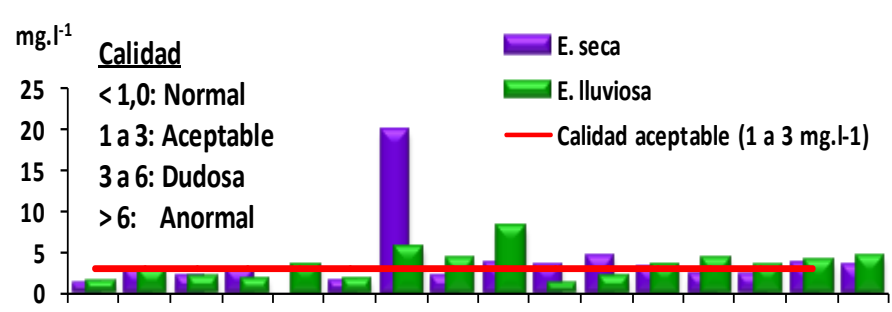

DQO
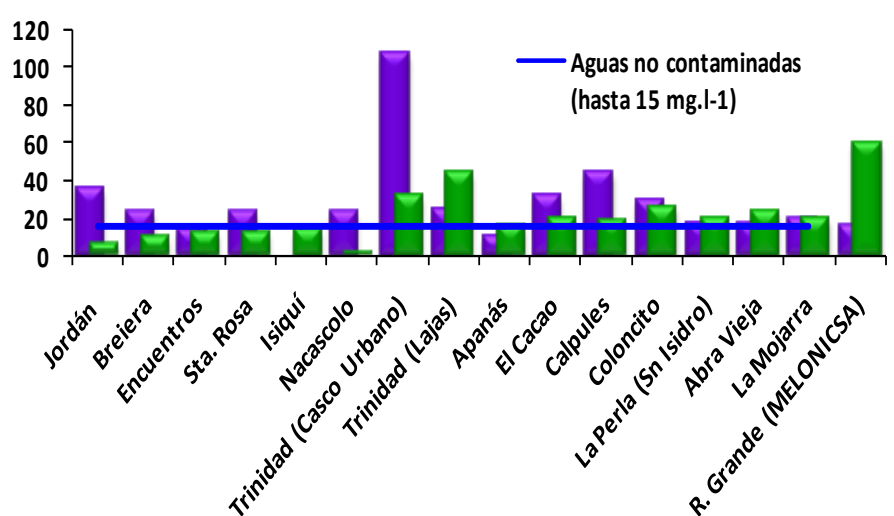

causas naturales (disminución drástica del caudal). Figura 1. Distribución espacial y temporal en la parte alta, media y baja de la subcuenca del Río Viejo. Criterios de calidad respecto a concentraciones de referencia (DBO $:$ Ramirez \& Viña, 1998; DQO: Custodio \& Llamas, 2001).
Según los índices y valores obtenidos (CE, elementos fitotóxicos, SAR, CSR y PSI) indicaron aguas aptas para el riego $\left(\mathrm{C}_{1}-\mathrm{S}_{1}\right.$ y $\left.\mathrm{C}_{2}-\mathrm{S}_{1}\right)$, excepto Nacascolo, TrinidadCasco Urbano y Trinidad-Las Lajas durante la época seca que es precisamente cuando se presenta la mayor demanda por el recurso para uso agrícola, debido al incremento de los niveles de CSR que las hace poco recomendables (Ayers \& Wescot, 1984) (U.S. Salinity Laboratory Staff, 1954).

\section{Contaminantes metálicos y orgánicos}

Respecto a los contaminantes metálicos (arsénico, cadmio y mercurio en agua y sedimento), solamente en algunos sitios se cuantificaron niveles ligeramente mayores que el límite de detección de los respectivos métodos, para los cuales se presume un origen natural, siendo menores a los valores de referencia para la protección de la vida acuática en sistemas de aguas dulces (Canadian Counsil of Ministers of the Environment (CCME), 2008) y muy inferiores a los de aguas no contaminadas (World Health Organization (WHO), 2008).

De los tres grupos de plaguicidas analizados, se detectaron cinco compuestos organoclorados (Gamma $\mathrm{HCH}$, Heptacloro, Dieldrín, Endrín y Alfa-endosulfano (I)), siendo el Dieldrín el más frecuente. Éste se cuantificó en Río Grande en MELONICSA junto con el Endrín en Trinidad-Casco Urbano en la época seca en valores similares a los recomendados para la protección de la vida acuática (Canadian Counsil of Ministers of the Environment (CCME), 2008). La presencia de estos plaguicidas hace presumir que sea producto de la persistencia de los mismos en el suelo asociada con su amplia utilización en el pasado y/o el uso actual no obstante su prohibición, lo cual conlleva a sugerir el establecimiento efectivo de medidas de control sobre las actividades agrícolas.

Se detectó un compuesto organofosforado, el insecticida Fentión (1,46 ng.1-1) en Trinidad-Casco Urbano (parte media de la subcuenca) durante el muestreo de enero de 2011, indicando aplicaciones recientes y/o con bastante regularidad dada la diversidad de usos que presenta en las actividades agrícolas, pecuarias (antiparasitario) y urbanas. Sin embargo, se presume que debido a su corta vida media(3 a 21 días) en los cuerpos de agua y moderada persistencia en el suelo (vida media de 34 días) en la mayoría de las condiciones (Food and Agriculture Organization of the United Nations (FAO), 2000), además del fuerte efecto de dilución por las precipitaciones de la época, no favoreció la detección en los sitios restantes.

Aunque no se dispone de valores de referencia, se destaca que la toxicidad del Fentión es desde ligera a extrema 
para peces y desde moderada a extrema para moluscos. Esta varía de alta a extremadamente alta para anfibios, crustáceos, insectos (abejas), zooplancton, fitoplancton y aves (International Union of Pure and Applied Chemistry (IUPAC)).

\section{Áreas críticas}

A juzgar por lo observado in situ, todos los sitios de muestreo en distinto grado presentaron condiciones de alta vulnerabilidad producto de que se ejerce poco o ningún control sobre las actividades que se desarrollan en la subcuenca. Trinidad-Casco Urbano en la parte media de la subcuenca presentó condiciones ambientales y de calidad del agua críticas, afectado durante la época seca por valores bajos de oxígeno disuelto, los mayores de $\mathrm{DBO}_{5}$, de nitrógeno, de fósforo total y ortofosfato, así como el mayor número de plaguicidas detectados (2 organoclorados, 1 organofosforado y 1 carbamato). Según los resultados, este tramo responde de manera muy sensible a los aportes externos (receptor de aguas residuales domésticas) en función de los cambios naturales del régimen hidrológico, siendo que las lluvias le favorecen al actuar como un mecanismo eficiente de autodepuración.

Río Grande en MELONICSA, tramo final de toda la red fluvial, dejó en evidencia la fuerte influencia de las actividades agrícolas (desde Nacascolo y el área circundante de Apanás donde predomina el cultivo intensivo de hortalizas), por presentar las mayores concentraciones de Lindano y Dieldrín y servir de receptor de las aguas de retorno enriquecidas con nutrientes procedentes de extensas áreas con cultivo de arroz, lo cual merece consideración respecto al potencial de arrastre de sustancias tóxicas hacia el Lago Xolotlán.

\section{CONCLUSIONES}

El agua en la mayoría de los sitios presenta características físico-químicas naturales que le confieren, de manera particular para El Jordán excelente calidad para consumo humano, destacando la importancia de involucrar además los indicadores microbiológicos de contaminación por su implicación en la salud y, en general, buena calidad para el riego y recreación, así como óptimas condiciones para soportar la vida acuática, según los valores $\mathrm{y}$ criterios establecidos por las diferentes Normas.

Excepcionalmente se identificó Trinidad-Casco Urbano como el sitio en condiciones ambientalmente críticas, donde las lluvias le favorecen al actuar como un mecanismo eficiente de autodepuración respecto a los indicadores de contaminación por materia orgánica y de nutrientes.
La detección de plaguicidas organoclorados (Endrín, Heptacloro y Lindano) en la parte alta, media y baja de la subcuenca parece indicar que continúan siendo utilizados en la agricultura de manera ilegal.

\section{RECOMENDACIONES}

Diseñar un programa para la construcción progresiva de sistemas domiciliarios de tratamiento de aguas grises en las zonas rurales, así como la implementación de un manejo adecuado de los desechos sólidos y líquidos en las zonas urbanas.

Establecer un sistema efectivo de control sobre las actividades humanas (agricultura, ganadería, domésticas) que se desarrollan principalmente en zonas aledañas a las fuentes superficiales tanto en sectores rurales como urbanos.

\section{BIBLIOGRAFÍA}

American Public Health Association (APHA). (2005). Standard Methods for the Examination of Water and Wastewater. 21th. Washington: Washington: APHA.

Ayers, R., \& Wescot, D. (1984). La calidad del agua en la agricultura. FAO. Roma, Italia.

Canadian Counsil of Ministers of the Environment (CCME). (2008). Canadian Environmental Quality Guidelines. Winnipeg: Canadian Counsil of Ministers of the Environment.

Canadian Counsil of Ministers of the Environment (CCME). (2008). Canadian Water Quality Guidelines (CWQG). Ottawa, Ontario, Canada.

CAPRE. (1994). Normas de Calidad del Agua para Consumo Humano. Comité Coordinador Regional de Instituciones de Agua Potable y Saneamiento de Centro América, Panamá y República Dominicana. $1^{a}$ Edición. Costa Rica.

Crumpton, W. T. (1992). Nitrate and $N$ analisis with secondderivate spectroscopy. Lymnology \& Oceanography , 37: 907-913.

Custodio, E., \& Llamas, R. (2001). Hidrología subterránea. Tomo I. (Segunda ed.). Barcelona, España: Ediciones Omega, S. A.

Food and Agriculture Organization of the United Nations (FAO). (2000). Food and Agriculture Organization of the United Nations (FAO). 
Recuperado el 12 de Enero de 2011, de Food and Agriculture Organization of the United Nations (FAO):

http://www.fao.org/docrep/005/x2570s/X2570S10

$\underline{. h t m}$

International Union of Pure and Applied Chemistry (IUPAC). (s.f.). IUPAC. Recuperado el 12 de Abril de 2011, de IUPAC: WWW.ine.gob.mx/dgicurg/plaguicidas/pdf/oxami l.pdf

Ramirez, A., \& Viña, G. (1998). Limnología Colombiana. Aportes a su conocimiento y estadísticas de análisis. (Primera ed.). Fundación Universidad de Bogotá

Jorge Tadeo Lozano.

Rodier, J. (1981). Análisis de las Aguas Naturales, Aguas Residuales y Aguas de Mar. España: Ediciones Omega.

Roldán, G., \& Ramírez, J. J. (2008). Fundamentos de limnología neotropical.Medellín: Editorial Universidad de Antioquia.

U.S. Salinity Laboratory Staff. (1954). Diagnosis and improvement of saline and alkali soils. Handbook 60. U.S. Gov. Print Office, Washington, D.C.

Wetzel, R. (2001). Limnology. Lake and River Ecosystems. San Diego, California, United States of America: Elsevier Academic Press.s

World Health Organization (WHO). (2008). Guidelines for Drinking-water Quality. Geneva. 